\title{
ENSO regulation of far- and mid-infrared contributions to clear-sky OLR
}

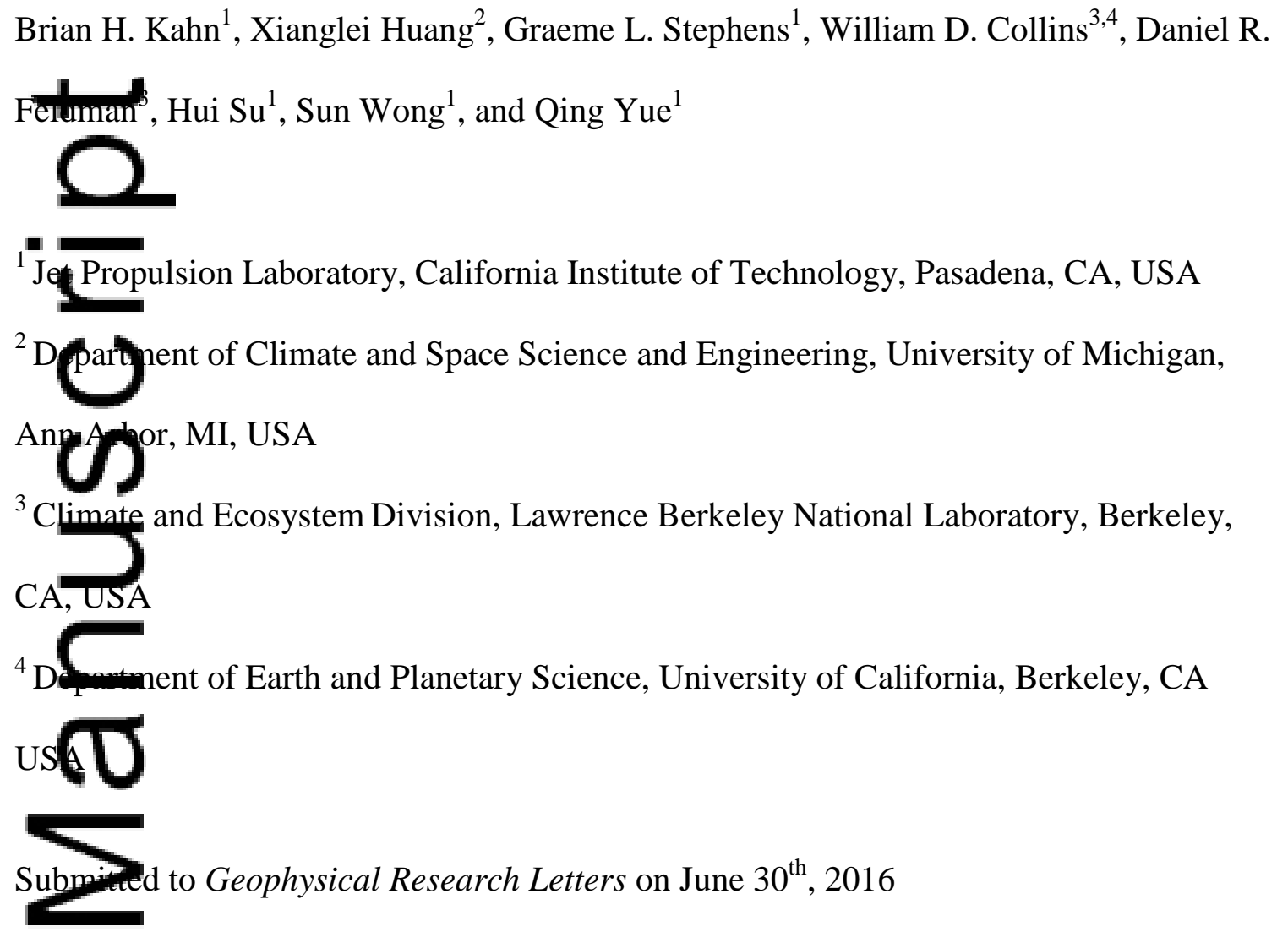

Corresponding Author: Brian H. Kahn, Jet Propulsion Laboratory, 4800 Oak Grove Drive, Mail Stop 233-302, Pasadena, CA, 91109, USA; Tel. 310-795-0960; Email: brian.r..kahn@jpl.nasa.gov

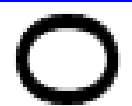

Key_Point \#1: ENSO modulated variations in tropical-extratropical mixing are observed in $\mathrm{Tr}-\mathrm{IR}$ and $6.3 \mu \mathrm{m}$ emission bands.

Keyroint \#2: The ratio of far- and mid-IR emission, and its temporal and spatial varion are closely linked to the atmospheric circulation and water vapor abundance.

Key Point \#3: The importance of the far-IR in the context of present-day moist tropical pee ses is highlighted.

This is the author manuscript accepted for publication and has undergone full peer review but has not been through the copyediting, typesetting, pagination and proofreading process, which may lead to differences between this version and the Version of Record. Please cite this article as doi: 10.1002/2016GL070263

This article is protected by copyright. All rights reserved. 


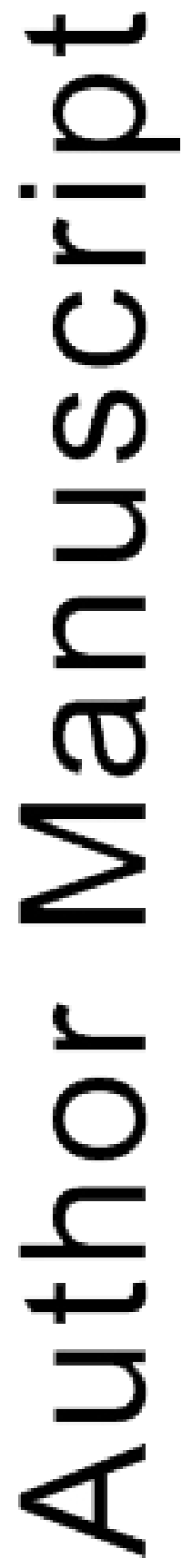

This article is protected by copyright. All rights reserved. 


\begin{abstract}
NASA Aqua-derived thermodynamic profiles, calculated spectral clear-sky outgoing longwave radiation (OLR), and vertical velocity fields from meteorological reanalyses are amined to determine the relative proportion of the far-infrared (FIR) and midinfured (MIR) spectral contributions to the total clear-sky OLR during different phases of NSt In the ascending branch of the tropical circulation, the spatial variance of upper troposheric water vapor is shown to be larger during La Niña than El Niño and is consistent with zonal symmetry changes in the tropical waveguide and associated tropical-extratropical mixing. In the descending branch, upper tropospheric water vapor shomer coupling to lower layers that is evidenced by changes in the ratio of FIR to MI the clear-sky OLR. Diagnostics from the Geophysical Fluid Dynamics Lavatory (GFDL) AM3 model simulation are generally similar to satellite data but the rativeriR to MIR is 5-10\% larger with respect to dynamic regime.
\end{abstract}

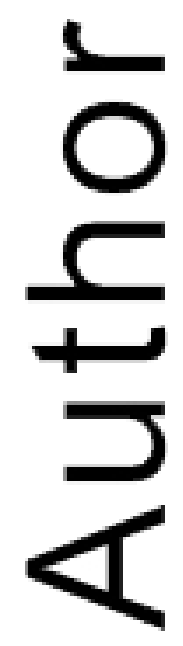




\section{Introduction}

The spread of climate sensitivity determined from climate GCMs remains large and varjes by a factor of 2.5 among climate models [IPCC, 2013]. Future changes in the glo argirculation are uncertain and are linked to an ensemble of moist atmospheric processes that are in turn coupled to the global circulation over a wide range of temporal 1 and spatral scales [e.g., Sherwood et al., 2010; Su et al., 2014]. One pathway in which the clealo tropical atmosphere is thought to play a key role in controlling the global cirdution response is through upper tropospheric (UT) moistening from convection and the mod lation of the greenhouse effect [e.g., Ramanathan and Collins, 1991; Su et al., 200 0]. Stnha and Harries [1995] showed that the maximum greenhouse forcing from uppar-tropospheric (UT) water vapor $(\sim 200-600 \mathrm{hPa})$ is located in the $250-500 \mathrm{~cm}^{-1}$ spectral region. Global top-of-atmosphere (TOA) observations in the far-infrared (FIR $>15$ spectral region are needed given the unambiguous moistening within the tropical UT [Soden et al., 2005] and evidence for a "super greenhouse" effect in climate s. models [Stephens et al., 2016]. There is also a need for more advanced climate obstruaton strategies [Wielicki et al., 2013] that include more complete coverage of Earh's infrared spectrum.

Troughly half of the Earth's surface and atmospheric radiation is emitted to space in the Infrared (MIR $<15 \mu \mathrm{m}$ or $>667 \mathrm{~cm}^{-1}$ ) and the other half in the FIR [Harries et 208]. A vast majority of the UT emission in the MIR region originates from the 6.3 
$\mu \mathrm{m}$ vibrational $\nu_{2}$ band $\left(1400-1650 \mathrm{~cm}^{-1}\right)$. Motivated by our investigation of moist UT processes, the proportion of FIR rotational band emission relative to the $6.3 \mu \mathrm{m}$ emission can be expressed as a ratio of FIR/6.3 $\mu \mathrm{m}$ emission. The ratio is known to be highest in the moist tropical atmosphere and the cold, dry polar latitudes, while it is lowest in the clearranury low and mid-latitudes [Clough et al., 1992; Slingo et al., 1997]. GCM -

con narisons with spectral OLR observations show that biases in discrete bands of a few hur dred of $\mathrm{cm}^{-1}$ in width may be several factors higher than the mean bias obtained fro 19 full infrared spectrum. This result points to compensating modeling errors betweendifferent spectral regions [Huang and Ramaswamy, 2008; Huang et al., 2014] and the_importance of making spectral observations in the FIR to improve general circulation models (GCMs). Furthermore, the spectral variations of the FIR and MIR acros relevant time and spatial scales of the diurnal, seasonal, and inter-annual cycles remanyoorly understood. There is a paucity of observations in the FIR [Cox et al., 2007; Mlynczak et al., 2006] with approximately 7 orders of magnitude more existing remote senfing observations in the MIR than the FIR.

Sate lite-derived thermodynamic profiles, calculated spectral OLR observations using a ratrate transfer model constrained by observations, and pressure velocity fields obthined from meteorological reanalyses are combined to quantify the proportion of FIR and $\overline{M I I y}$ in the clear-sky radiative response to moistening and drying in the low latitudes. El Niñ Southern Oscillation (ENSO) dominates the present-day inter-annual variability. 
Based on the previous works of Pierrehumbert and Yang [1993], Waugh and Polvani [2000], and other studies that linked inter-annual variability with tropical-extratropical mixing processes, we hypothesize that ENSO modulates the relationship between UT moistening (drying) and large-scale dynamical regimes, and in turn, the spectral chatictics of clear-sky OLR. We explore these relationships and compare the conbined satellite-reanalysis diagnostics to the output from the Geophysical Fluid Dy amis Laboratory (GFDL) AM3 climate general circulation model (GCM). We focus on pectral regions with emission originating in the UT (FIR: $10-560 \mathrm{~cm}^{-1}, 6.3$ : $\left.1400-1650 \mathrm{~cm}^{-1}\right)$. We use the ratio of FIR to 6.3 as a proxy for the relative contributions of each band to the total clear-sky OLR.

\section{工 \\ 2. Dta and Methodology}

Well-characterized and validated temperature and water vapor profiles from the Aurvopmeric Infrared Sounder (AIRS) [Chahine et al., 2006] Version 6 release are used within clear and partially cloudy conditions. Sea surface temperatures $\left(T_{\mathrm{scc}}\right)$ are obtained from real-time global analysis provided by the National Centers for Environmental Prediction (NCEP) and are matched to every AIRS footprint. Collocated Aqua AIRS and CTouds and the Earth's Radiant Energy System (CERES) observations are used to infer Clouds and spear resolved clear-sky OLR at $10 \mathrm{~cm}^{-1}$ resolution spanning from $10-2000 \mathrm{~cm}^{-1}$ [Chen etal., 2013]. Gridded monthly-averaged, $500 \mathrm{hPa}$ pressure velocity fields at $<$ 
$1.25^{\circ} \times 1.25^{\circ}$ from the Modern Era Retrospective-Analysis for Research and Applications (MERRA) reanalysis [Rienecker et al., 2011] are used to establish a link between water vapor, spectral OLR, and large-scale vertical motion on monthly time scales.

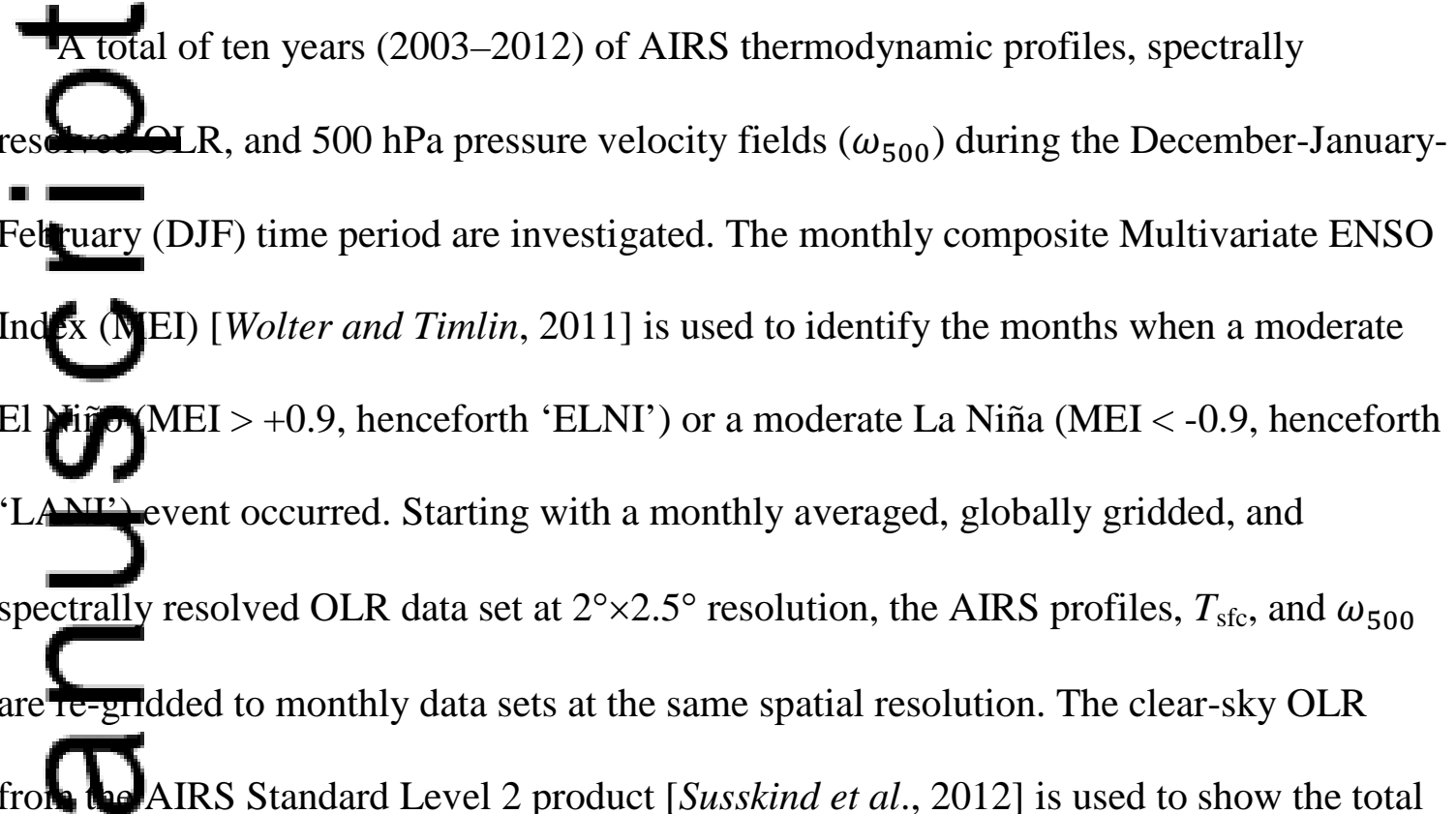
frow the AIRS Standard Level 2 product [Susskind et al., 2012] is used to show the total clearsy OLR, as the spectrally-resolved OLR data set contains only $97-98 \%$ of the total
OLR between $10 \mathrm{~cm}^{-1}$ and $2000 \mathrm{~cm}^{-1}$. AIRS profiles are retained for clear-sky and parially cloudy regions for all pressure levels of "good" quality [c.f., Yue et al., 2013; Wo $\lg$ etal., 2015], while $\omega_{500}$ is averaged over all values of cloud fraction. Zelinka and Ha morn [2009] illustrate the physical reasoning for this approach since the UT moistening is a direct consequence of convective detrainment for an ensemble of discrete small-sogle convective events. Thus, if $\omega_{500}$ is filtered for the same cloud fraction values 
as AIRS profiles, the convective cores that are ultimately responsible for the adjacent clear-sky moistening will not be included.

For comparison purposes, the clear-sky flux is calculated for the same FIR and $6.3 \mu \mathrm{m}$ barids using 6-hourly output from the GFDL AM3 model simulations that are forced by obsist from 2003 to 2012 using the radiative transfer model in Chen et al. [2013].

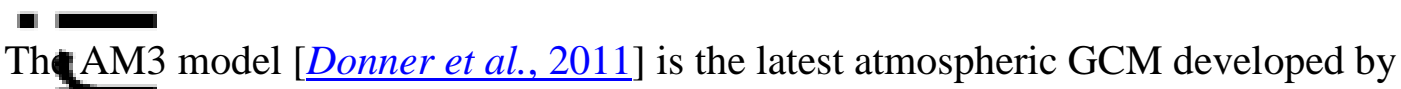
GF $\rho$ L With a horizontal resolution of $2.5^{\circ}$ longitude by $2^{\circ}$ latitude and 48 vertical levels. Cy hakara et al. [1979] and Stephens [1990] showed that imprints of the global ciremlation are obtained as deviations of column water vapor $\left(w_{C O L}\right)$ from a climatological average $\bar{w}_{C O L}$ that is approximated from binned values of $T_{\text {sfc }}$, and is expressed as $\widehat{w}_{C O L}=\left(w_{C O L}-\bar{w}_{C O L}\right) / w_{C O L}$. Positive (negative) values imply an excess (deliclof water vapor and all terms are averaged at $2^{\circ} \times 2.5^{\circ}$ resolution. Similarly, in this work define an analogous parameter between $150-400 \mathrm{hPa}$ as a proxy for UT column water vapor as $\widehat{w}_{U T}=\left(w_{U T}-\bar{w}_{U T}\right) / w_{U T}$. Both $\widehat{w}_{C O L}$ and $\widehat{w}_{U T}$ reflect vertical redstributions of moisture by circulation regime and spectral OLR variations. Other def nitio is of $\widehat{w}_{U T}$ with AIRS pressure levels as low as $700 \mathrm{hPa}$ were considered but are gen erary similar with reduced structure in the relationships.

The clear-sky total OLR generally increases with $T_{\text {sfc }}$ and a weak dependence of OLR on $w_{C O L}$ is found for $T_{\mathrm{sfc}}<295 \mathrm{~K}$ (Figs. 1a and 1b). The dependence however becomes much stronger for $T_{\text {sfc }}>295 \mathrm{~K}$ with a reduction in OLR of approximately $20-25 \mathrm{Wm}^{-2}$

across the observed range of $w_{C O L}$ at $T_{\mathrm{sfc}} \approx 300 \mathrm{~K}$. Significant scatter is observed on eithof $\bar{w}_{C O L}$. Although these results are in very close agreement with Raval et al. -

[194; c.f. Fig. 5], the gradients in clear-sky OLR with $w_{C O L}$ appear to be sharper than inf (red) rom the Earth Radiation Budget Experiment (ERBE) data that are possibly relace the smaller fields of view of both AIRS and CERES, better clear and cloudy sky-imination, and improved instrumentation and processing algorithms.

A much broader amount of scatter is observed for $w_{U T}$ especially for $T_{\mathrm{sfc}}>297 \mathrm{~K}$ (Figs. Ic and 1d). The sharp increase in $w_{U T}$ occurs over a very small increase in $T_{\text {sfc }}$ and is nared by a dramatic decrease in clear-sky OLR. The ratio of the FIR $\left(10-560 \mathrm{~cm}^{-1}\right)$ to the $3 \mathrm{~m}$ MIR (1400-1650 $\mathrm{cm}^{-1}$ ) water vapor bands with respect to clear-sky OLR is shown in Figs. 1e and 1f, with the largest ratios found in the coolest and driest regions of the extratropics and the tropical super greenhouse regions [Stephens et al., 2016]. The hig val es of the ratio are consistent with the reduction in broadband OLR with inc easming $T_{\text {sfc }}$ due to the super-Clausius Clapeyron increase in $w_{U T}$ through convective moistening [Huang and Ramaswamy, 2008; Su et al., 2006]. (As an aside, we note that the ratio is high in the extratropics because of the frequency shift in Planck emission toward-1onger wavelengths). The largest ENSO differences occur for $T_{\mathrm{sfc}}>297 \mathrm{~K}$ and 
furthermore broader scatter is observed in LANI (Fig. 1c) than ELNI (Fig. 1d) at lower $T_{\text {sfc. }}$

The ratio of FIR/6.3 OLR increases with increasing $w_{U T}$ and decreasing OLR (Fig. 1g ana-m). Of particular note is the amount of scatter in the ratio at a fixed value of clearsky This scatter varies by $5-15 \%$ of the mean value of the ratio depending on the manitude of OLR. The scatter is tied to variability in other geophysical factors such as tem perayure lapse rate [e.g., Allan et al., 1999]. This demonstrates the absence of a unifurationship between clear-sky OLR and the contributions from the $6.3 \mu \mathrm{m}$ and FIR solutions that cause spectral OLR compensation within climate GCMs [Huang et al., 201 inspection of more limited time periods reveals that the scatter in the FIR/6.3 rationdens further, pointing to the importance of measuring the spectral OLR over a vary of temporal and spatial scales. Results for the GFDL model are shown in Fig. S1
ana pomt to further reductions in clear-sky OLR, and increases in $w_{U T}$ relative to Fig. 1, corsistent with a FIR/6.3 ratio that is 5-10\% larger than shown in Fig. 1. There is also sub (e ENSO variability observed in the GFDL model (Fig. S1) but is structured sommat differently than Fig. 1. The spatial patterns of $\widehat{w}_{C O L}$ and $\widehat{w}_{U T}$ derived from AIRS profile data over the 10 yearTJ time period are shown in Fig. 2. The spatial pattern of $\widehat{w}_{C O L}$ (Figs. 2b and 2d) agreestry well with Stephens [1990] showing convective moistening in the tropical 
western Pacific, portions of the ITCZ, and extensive regions of the extratropical storm tracks. The spatial pattern of $\widehat{w}_{U T}$ (Figs. 2a and 2c) is however greatly amplified and also spatially shifted compared to $\widehat{w}_{C O L}$. In the tropical western Pacific, note that while the spatral pattern is quite similar with a larger magnitude, the total area encompassed by pos values is spatially larger, indicating that some regions simultaneously have $\widehat{w}_{U}>0$ and $\widehat{w}_{C O L}<0$. In the tropical eastern Pacific and Atlantic, however, the $\widehat{w}_{U T}$ patern different than $\widehat{w}_{C O L}$, implying that much of the tropical UT is very dry $\left(\widehat{w}_{U T}<0\right)$ eve 1 he case of a moist column $\left(\widehat{w}_{C O L}>0\right)$. The spatial distributions also suggest that the ropics are more likely than the tropics to have a positive $\widehat{w}_{U T}$ instead of $\widehat{w}_{C O L}$. Results for the GFDL model (Fig. S2) show spatially similar patterns with slightly larger values or $\widehat{w}_{C O L}$ and reduced values of $\widehat{w}_{U T}$ in the low and midlatitudes compared to Fig. 2. AdeNSO variations in Figs. 2 and S2 are spatially similar; however, some differences in the extratropics are observed, and a larger ENSO variation found in the The moist and dry anomalies are spatially redistributed with ENSO variations (LANI mi us BNI). Moistening occurs during LANI in the UT to the north and south of the tropestern Pacific warm pool region, in proximity of and to the south of Hawaii, the Caribbean Sea, and the north Atlantic tropics, while ELNI shows dramatic moistening in the central equatorial Pacific region near the dateline. The spatial redistributions are closely to redistributions of vertical ascent associated with shifting convection [e.g., 
Soden, 1997] and are clearly seen in $\omega_{500}$ fields [Su and Jiang, 2013; cf. Fig. S3]. In the tropical western Pacific, the ENSO anomalies of $\widehat{w}_{U T}$ are spatially similar to $\widehat{w}_{C O L}$ but are significantly stronger in magnitude; this suggests strong vertical coupling between the UTand underlying atmospheric layers. However, in the tropical eastern Pacific, the $\widehat{w}_{U T}$ are different than $\widehat{w}_{C O L}$ suggesting (1) large changes in the vertical - structure of the global circulation response with respect to ENSO variability and (2) $\mathrm{mu}$ waker vertical coupling between the UT and underlying atmospheric layers in the desperging branch of the Walker circulation.

The quivalent total clear-sky OLR and FIR/6.3 ratio are shown in Fig. 3. The zonal symmetry is enhanced during ELNI [e.g., Webster and Holton, 1982; Waugh and Polveru, 2000] while the zonal asymmetry is enhanced in LANI. While the ENSO varatos of the FIR/6.3 ratio demonstrate coherence, the spatial patterns are noisier than clearsy OLR variations and point to non-uniqueness in spectral OLR variations. Very fewereat-sky data points populate the convectively active regions over tropical Africa and the Amazon in South America because of persistent cloudiness regardless of the pha ENSO. Results for the GFDL model (Fig. S4) show reduced clear-sky OLR by $5-15 \mathrm{Wm}^{-2}$ in the tropics and an increase in the FIR/6.3 ratio of 5-10\% compared to Fig. 3. T Tho $\widehat{v}_{U T}$ and $\widehat{w}_{C O L}$ are sorted by $\omega_{500}$ into $10 \mathrm{hPa} \mathrm{d}^{-1}$ bins in Figs. $4 \mathrm{a}$ and $4 \mathrm{~b}(4 \mathrm{~d}$ and 4e for GFDL), and are further subdivided into ELNI (red) and LANI (blue). The $\widehat{w}_{U T}$ and 
$\widehat{w}_{C O L}$ both show increased moistening with ascent [Hallberg and Inamdar, 1993; Bony et al., 1997] and increased drying with descent. However, the rate of moistening and drying with respect to $\omega_{500}$ is a factor of $2-5$ higher for $\widehat{w}_{U T}$ compared to $\widehat{w}_{C O L}$ in Aqua data and show ws the inherent sensitivity of UT water vapor to dynamical regime [Bony et al., 1997; Che al., 1998]. Similar sorting of $\widehat{w}_{U T}$ and $\widehat{w}_{C O L}$ by $\omega_{500}$ is found for both ELNI and LANI although we caution that detecting subtle differences requires a much lon er a statistically significant record of ENSO variations. Results for the GFDL

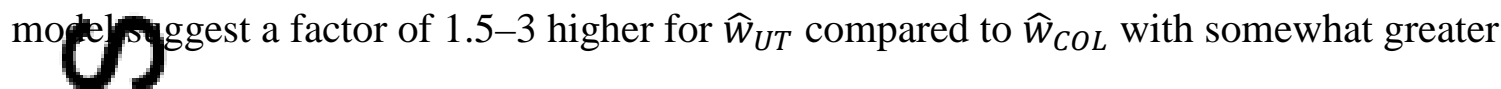
diffares between ELNI and LANI than the satellite data.

The variance of $\widehat{w}_{U T}$ and $\widehat{w}_{C O L}$ is shown with the spread in the colored shading. There are firre features to highlight. First, the variance in $\widehat{w}_{C O L}$ is less than $\widehat{w}_{U T}$. Second, the var ind is significantly less in regions of ascent compared to descent. Third, the variance is rarge yet nearly identical for ELNI and LANI in regions of descent. However, in
regions of ascent, the variance is typically a factor of $1.5-2 \times$ higher during LANI for both $\widehat{w}_{U}$ and $\widehat{w}_{C O L}$ (Figs. 4a, 4b, 4d, and 4e) although the magnitude remains particularly sm(11 fo $\widehat{w}_{C O L}$. On average, the variance is much larger in the descending branch of the tro carculation but the magnitude of variance is generally similar between the phases of FNSS.

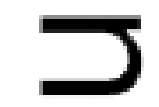
4. Dipetission 
Spectral observations in the FIR (mean and variance), especially in moist lowlatitude regions, may yield additional insight on important mixing processes and impacts on the radiation budget that operate in climate models. Pierrehumbert and Yang [1993] showeat that tropical mixing is likely dominated by cross-isentropic transport from dia atioheating of convective latent heat release and radiative cooling in clear [e.g., Allet et al., 1999; Feldman et al., 2008] and cloudy skies [e.g., Mather et al., 2007]. GCIIs a known to artificially diffuse small-scale structures that are generated by mixingrocesses [e.g., Skamarock, 2004] and in turn may inadvertently enhance meridional transport through the tropical mixing barrier [Webster and Holton, 1982]. This transport may lead to unrealistic spatial homogenization of small-scale humidity fiel to excessive drying in the tropics and moistening in the extratropics. Piertumbert and Yang [1993] emphasize how these mixing processes could modulate prent-day climate variability and anthropogenic climate change. Global observations of thereat small spatial scales and with frequent revisits that resolve UT deep convective and clear-sky moist processes may help shed light on the nature of turbulent mixing processy in the UT.

Waygh and Polvani [2000] showed that subtropical intrusions into the tropics are less common in ELNI compared to LANI. The upper tropospheric westerlies are weaker 1. during LNI and imply less mixing between subtropical and extratropical air. A more zonally symmetric tropical waveguide is observed during ELNI, which is also observed $<$ 
in vertically resolved water vapor [Blankenship and Wilheit, 2001], with small enhancements of moisture between $\pm 10^{\circ} \mathrm{N} / \mathrm{S}$ and drying between $\pm 10-20^{\circ} \mathrm{N} / \mathrm{S}$ between

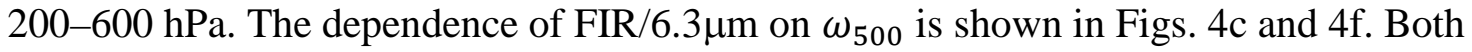
ELNI and LANI show similar dependences in the relative contribution of the FIR with respectut 500 . The differences in the variance of the ratios between ELNI and LANI are - -

suble but are more apparent in the GFDL model. Interestingly, this behavior does not ma(to the clear-sky OLR dependence (Fig. S5). A larger discrepancy in the mean clearsky 93 in ascending regions compared to descending regions, and a larger discrepancy in the ince in descending regions compared to ascending regions, is noted between Aqua and GFDL.

Previously published works on tropical-extratropical mixing are consistent with the deponthe of $\widehat{w}_{U T}$ and $\widehat{w}_{C O L}$ variances on the phase of ENSO and further motivate spectray FIR measurements as additional observational constraints on tropical variability (cf. Fig. S6). Our analysis suggests that additional FIR measurements are warranted to furher connect the tropical circulation and energy transport to present-day climate var abili)y (e.g., ENSO) and future climate change [Stephens et al., 2016]. This work em crasized the moderate ENSO variations during the 2003-2012 time period (no DJF ocourrences in 2013 and 2014 met the MEI criteria). Future work will focus on the charactg ization of the strong ENSO event during 2015-2016 and the degree of similarity betweamoderate and strong ENSO events. 


\section{Summary}

A record of NASA Aqua AIRS-derived thermodynamic profiles, spectral clear-sky ODKovtained from collocated AIRS and CERES observations, and mid-tropospheric ver alalocity from MERRA reanalysis are used to assess the relative roles of the farinfured (FIR) and mid-infrared (MIR) spectral regions on the clear-sky tropical OLR.

We leanirm previous results that the FIR plays a dominant role over the warmest tropical Clanevron arguments.

Significant variations in ENSO are used as a proxy for present-day inter-annual varialidy to establish the relationship between moistening and drying as a function of dyranid regime, and in turn relate moisture changes to the magnitude of spectral OLR. In the ascending branch of the tropical circulation, the variance of upper tropospheric nuvorum is shown to be larger in the La Niña phase rather than the El Niño phase. This behavior is consistent with changes in the zonal symmetry of the tropical waveguide and ass erand tropical-extratropical mixing processes that control moisture variability. In the descending branch of the tropical circulation, the variations of upper tropospheric water vapor deviate significantly from lower atmospheric layers, suggesting weaker vertical coumling moist processes. These behaviors were to first order reproduced in the GFDL AM3 mgdel. However, small yet systematic differences in the FIR/6.3 ratio, clear-sky




OLR, upper tropospheric water vapor, and their variances with ENSO variability were described. Subtle discrepancies in the spectral OLR between satellite/reanalysis observations and the GFDL model, and their coupling to the atmospheric circulation, surgest the value of diagnostics linking radiation and dynamics.

Aldscale spectral band observations in the FIR may help shed light on a wide range of upper tropospheric moist processes that are poorly characterized over a range of spa al and temporal scales. These moist processes are relevant in the context of current climat ariability and potentially anthropogenic climate change that could lead to

systematic changes in the dominant types of El Niño [Yeh et al., 2009].

Actedgments

A 1 iid of this research was carried out at the Jet Propulsion Laboratory (JPL),

Cantornia Institute of Technology, under a contract with the National Aeronautics and Spatratministration. We thank two anonymous reviewers for very constructive feedback and insights that led to an improved manuscript. B. Kahn was supported by

Strogy University Research Partnership (SURP) proposal between JPL and the University of Michigan. X. Huang was supported by NASA under grant NNX14AJ50G

awarded to the University of Michigan. D. Feldman and W. Collins acknowledge support $+$

by Separtment of Energy, Office of Science, Office of Biological and Environmental Research, Terrestrial Ecosystem Science and Atmospheric System 
Research programs, under award number DE-ACO2-05CH11231. The AIRS version 6 data sets were processed by and obtained from the Goddard Earth Services Data and Information Services Center (http://daac.gsfc.nasa.gov/). The MERRA data sets were processed by and obtained from the NASA Goddard's Global Modeling and Assimilation Of (A) 2016. All rights reserved. Government sponsorship acknowledged.

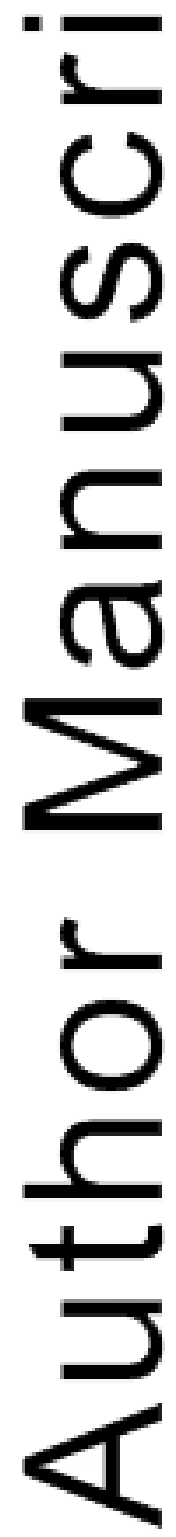




\section{References}

Allan, R. P., K. P. Shine, A. Slingo, and J. A. Pamment (1999), The dependence of clearsky outgoing long-wave radiation on surface temperature and relative humidity, Q. J.

+.Meteorol., Soc., 125, 2103-2126.

Bla 2 hip, C. B., and T. T.Wilheit (2001), SSM/T-2 measurements of regional

- changes in three-dimensional water vapor fields during ENSO events, J. Geophys. Res. 106, 5239-5254.

Bopy K.-M. Lau, and Y. C. Sud (1997), Sea surface temperature and large-scale circulation influences on tropical greenhouse effect and cloud radiative forcing, $J$. Climate, 10, 2055-2077.

Ch au, J.-P., A. Chédin, and N. A. Scott (1998), Relationship between sea surface tenerature, vertical dynamics, and the vertical distribution of atmospheric water Wapor inferred from TOVS observations, J. Geophys. Res., 103, 23,173-23,180.

Cratrme, M. T., T. S. Pagano, H. H. Aumann and Coauthors (2006), The Atmospheric Infrared Sounder (AIRS): Improving weather forecasting and providing new insights (Ito climate, Bull. Amer. Meteor. Soc., 87, 911-926, doi: 10.1175/BAMS-87-7-911.

Chen X. X. Huang, N. G. Loeb, and H. Wei (2013), Comparisons of Clear-Sky

Outgoing Far-IR Flux Inferred from Satellite Observations and Computed from the $+$

Most Recent Reanalysis Products. J. Climate, 26, 478-494. doi: 10.1175/ICLI-

D-12-00212.1

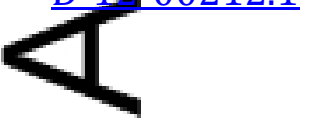

This article is protected by copyright. All rights reserved. 
Chen, X., X. Huang, and X. Liu, 2013: Non-negligible effects of cloud vertical overlapping assumptions on longwave spectral fingerprinting studies. J. Geophys. Res. Atmos., 118, 7309-7320, doi:10.1002/jgrd.50562.

Crougn, S. A., M. J. Iacono, and J.-L. Moncet (1992), Line-by-line calculations of Omdaneric fluxes and cooling rates: Application to water vapor, J. Geophys. Res., - 97, 15761-15785, doi: 10.1029/92JD01419.

Co C. V., J. E. Murray, J. P. Taylor, P. D. Green, J. C. Pickering, J. E. Harries, and A.

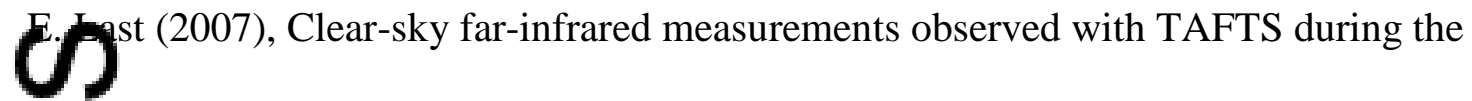
EAQUATE campaign, September 2004, Q. J. Royal. Met. Soc., 133, 273-283.

Donner, L. J., and Coauthors, 2011: The dynamical core, physical parameterizations, and simulation characteristics of the atmospheric component AM3 of the GFDL G(b) 1 coupled model CM3. J. Climate, 24, 3484-3519,

doi:10.1175/2011JCLI3955.1.

Fitrman, D. R., K. N. Liou, R. L. Shia, and Y. L. Yung (2008), On the information content of the thermal infrared cooling rate profile from satellite instrument Tiea urements, J. Geophys. Res., 113, D11118, doi: 10.1029/2007JD009041.

Hallbero R., and A. K. Inamdar (1993), Observations of seasonal variations in atmospheric greenhouse trapping and its enhancement at high sea surface

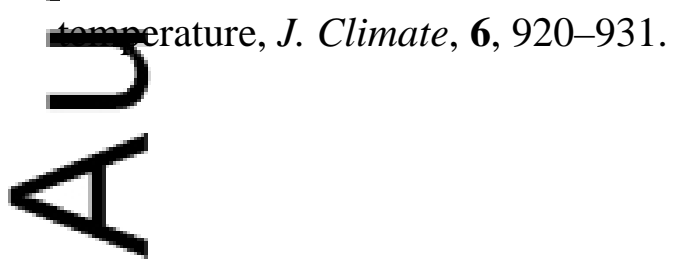


Harries, J., B. Carli, R. Rizzi, C. Serio, M. Mlynczak, L. Palchetti, T. Maestri, H.

Brindley, and G. Masiello (2008), The far-infrared Earth, Rev. Geophys., 46,

RG4004, doi: 10.1029/2007RG000233.

Hutng, X., X. Chen, G. L. Potter, L. Oreopoulos, J. N. S. Cole, D. Lee, and N. G. Loeb

A Global Climatology of Outgoing Longwave Spectral Cloud Radiative

Effect and Associated Effective Cloud Properties. J. Climate, 27, 7475-7492, doi:

10.1 75/JCLI-D-13-00663.1

Huang.y., and V. Ramaswamy (2008), Observed and simulated seasonal co-variations of outoging longwave radiation spectrum and surface temperature, Geophys. Res. Lett.,

35, L17803, doi:10.1029/2008GL034859.

IPC (13), Climate Change 2013: The Physical Science Basis. Contribution of Wering Group I to the Fifth Assessment Report of the Intergovernmental Panel on

Qlimate Change [Stocker, T.F., D. Qin, G.-K. Plattner, M. Tignor, S.K. Allen, J.

Eoshung, A. Nauels, Y. Xia, V. Bex and P.M. Midgley (eds.)]. Cambridge

University Press, Cambridge, United Kingdom and New York, NY, USA, 1535 pp,

(1018) $0.1017 / \mathrm{CBO} 9781107415324$.

Mather_J. H., S. A. McFarlane, M. A. Miller, and K. L. Johnson (2007), Cloud properties

and associated radiative heating rates in the tropical western Pacific, J. Geophys. Res.,

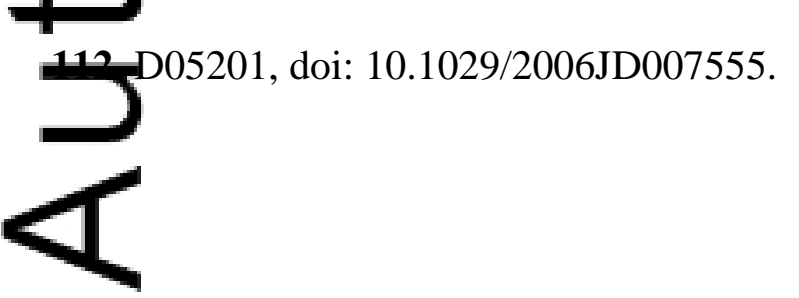

This article is protected by copyright. All rights reserved. 
Mlynczak, M. G., et al. (2006), First light from the Far-Infrared Spectroscopy of the Troposphere (FIRST) instrument, Geophys. Res. Lett., 33, L07704, doi:

10.1029/2005GL025114.

Pielrenumbert, R. T., and H. Yang (1993), Global chaotic mixing on isentropic surfaces, Cascis. Sci, 50, 2462-2480.

Praphakara, C., G. Dalu, R. C. Lo, and N. R. Nath (1979), Remote sensing of seasonal (isth bution of precipitable water vapor over the oceans and the inference of (2) dary-layer structure, Mon. Wea. Rev., 107, 1388-1401.

Ramanathan, V., and W. Collins (1991), Thermodynamic regulation of ocean warming by cirrus clouds deduced from observations of the 1987 El Niño, Nature, 351, 27-32.

Ra_. and V. Ramanathan (1989), Observational determination of the greenhouse efed, Nature, 342, 758-761.

Rava., A. H. Oort, and V. Ramaswamy (1994), Observed dependence of outgoing Norgave radiation on sea surface temperature and moisture, J. Climate, 7, 807-821.

Rienecker, M.M., M.J. Suarez, R. Gelaro, and Coauthors (2011), MERRA: NASA's Nocern-Era Retrospective Analysis for Research and Applications. J. Climate, 24, 3624-3648, doi: 10.1175/JCLI-D-11-00015.1.

Sherwood, S. C., R. Roca, T. M. Weckwerth, and N. G. Andronova (2010), Tropospheric -

vapor, convection, and climate, Rev. Geophys., 48, RG2001, doi:

10.1029/2009RG000301.

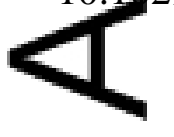

This article is protected by copyright. All rights reserved. 
Sinha, A., and J. E. Harries (1995), Water vapour and greenhouse trapping: The role of far infrared absorption, Geophys. Res. Lett., 22, 2147-2150.

Skamarock, W. C. (2004), Evaluating mesoscale NWP models using kinetic energy

Tspectra, Mon. Wea. Rev., 132, 3019-3032.

Slitand M. J. Webb (1997), The spectral signature of global warming, Q. J. Royal

Met. Soc., 123, 293-307.

Sogen, J. (1997), Variations in the tropical greenhouse effect during El Niño, $J$. Climate, 10, 1050-1055.

Soden B. J., D. L. Jackson, V. Ramaswamy, M. D. Schwarzkopf, and X. Huang (2005), The radiative signature of upper tropospheric moistening, Science, 310, 841-844.

Ste G. L. (1990), On the relationship between water vapor over the oceans and sea suface temperature, J. Climate, 3, 634-645.

Stophens, G. L., B. H. Kahn, and M. Richardson (2016), The super greenhouse effect in a Cirarging climate, J. Climate, 29, 5469-5482, doi:10.1175/JCLI-D-15-0234.1.

Su,H., W.G. Read, J. H. Jiang, J.W. Waters, D.L. Wu, and E.J. Fetzer (2006), Enhanced ossyve water vapor feedback associated with tropical deep convection: New evidence from Aura MLS, Geophys. Res. Lett., 33, L05709, doi:

10.1029/2005GL025505.

Su, H. Jiang, C. Zhai, T. J. Shen, J. D. Neelin, G. L. Stephens, and Y. L. Yung (2014), Weakening and strengthening structures in the Hadley Circulation change $\varangle$ 
under global warming and implications for cloud response and climate sensitivity, $J$. Geophys. Res., 119, 5787-5805, doi: 10.1002/2014JD021642.

Su, H., and J.H. Jiang (2013), Tropical clouds and circulation changes during the 2006-07 outgoing longwave radiation as observed by AIRS and CERES, J. Geophys. Res., ing in a zonally varying basic state, J. Atmos. Sci., 39, 722-733.

Wi liki B. A., D. F. Young, M. G. Mlynczak and Coauthors (2013), Achieving climate

hange absolute accuracy in orbit, Bull. Amer. Met. Soc., 94, 1519-1539.

W. K., and M. S. Timlin (2011), El Niño/Southern Oscillation behavior since 1871 as diagnosed in an extended multivariate ENSO index (MEI.ext), Int. J. Clim., 31,

\section{(07) 1087.}

Wong_S, E. J. Fetzer, M. Schreier, andF. W. Irion (2015), Cloud-induced uncertainties in Ind epptific Remitityps., 120, doi:

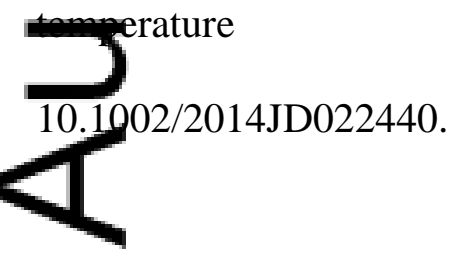


Yeh, S.-W., J.-S. Kug, B. Dewitte, M.-H. Kwon, B. P. Kirtman, and F.-F. Jin (2009), El Niño in a changing climate, Nature, 461, 511-515.

Yue, Q., E. J. Fetzer, B. H. Kahn, S. Wong, G. Manipon, A. Guillaume, and B. Wilson (2013), Cloud-state dependent sampling in AIRS observations based on CloudSat (10vassification, J. Climate, 26, 8357-8377.

Zelinka, M. D., and D. L. Hartmann (2009), Response of humidity and clouds to tropical Aeep convection, J. Climate, 22, 2389-2404.

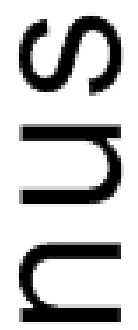

(ে
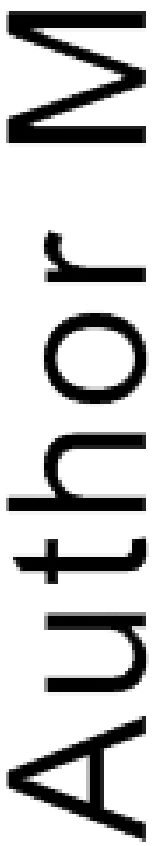

This article is protected by copyright. All rights reserved. 


\section{List of Figures}

Figure 1. (a and b) Scatter plot of $w_{C O L}(\mathrm{~mm})$ versus sea surface temperature $\left(T_{\mathrm{sfc}}\right)$ over clear-sky oceans that are limited to regions with $T_{\mathrm{sfc}}>280 \mathrm{~K}$ for warm (right column)

and cold (left column) phases of ENSO. The color scale is the clear-sky OLR $\left(\mathrm{Wm}^{-2}\right)$. Point represents a 10 -year DJF average at $2^{\circ} \times 2.5^{\circ}$ spatial resolution. The gray

- -

line is $\bar{w}_{C O L}$ following Stephens (1990) and Prabhakara et al. (1979) and is an average

for egch $T_{\text {sfc }}$ bin. (c and d) Similar to the upper left except for $w_{U T}$. (e and f) Clear-sky

O/A versus $T_{\text {sfc }}$ as a function of FIR/6.3. ( $\mathrm{g}$ and $\mathrm{h}$ ) Broadband clear-sky OLR versus OLR as a function of $w_{U T}$.

Figure 2. Shown are spatial maps of (a and c) $\widehat{w}_{U T}$ and (b and d) $\widehat{w}_{C O L}$ for the 10-year DJFlecord. LANI (ELNI) is in the upper (middle) row, and LANI-ELNI differences Qrid the lower row.

Figury 3 Shown are spatial maps of (a and c) clear-sky OLR from the AIRS Standard L2 product and (b and d) FIR/6.3 $\mu \mathrm{m}$ ratio from the spectrally-resolved OLR calculation for the 10-year DJF record. LANI (ELNI) is in the upper (middle) row, and LANIELN differences are in the lower row.

Fig tre 4. Shown is (a) $\widehat{w}_{C O L}$, (b) $\widehat{w}_{U T}$, and (c) FIR/6.3 $\mu \mathrm{m}$ ratio as a function of MERRA during ELNI (red) and LANI (blue). The $\pm 1 \sigma$ standard deviation of the monthly data vithin each $\omega_{500}$ bin is shown as the spread in the shading. The dashed lines

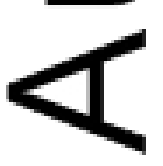


show the numbers of counts within each $\omega_{500}$ bin. Panels (d)-(f) are identical to (a)-

(c) except for the GFDL AM3 model.

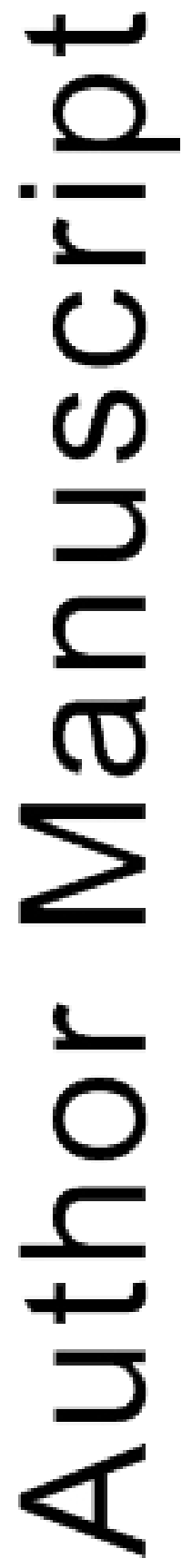





2016GL070263-f01-z-.jpg 

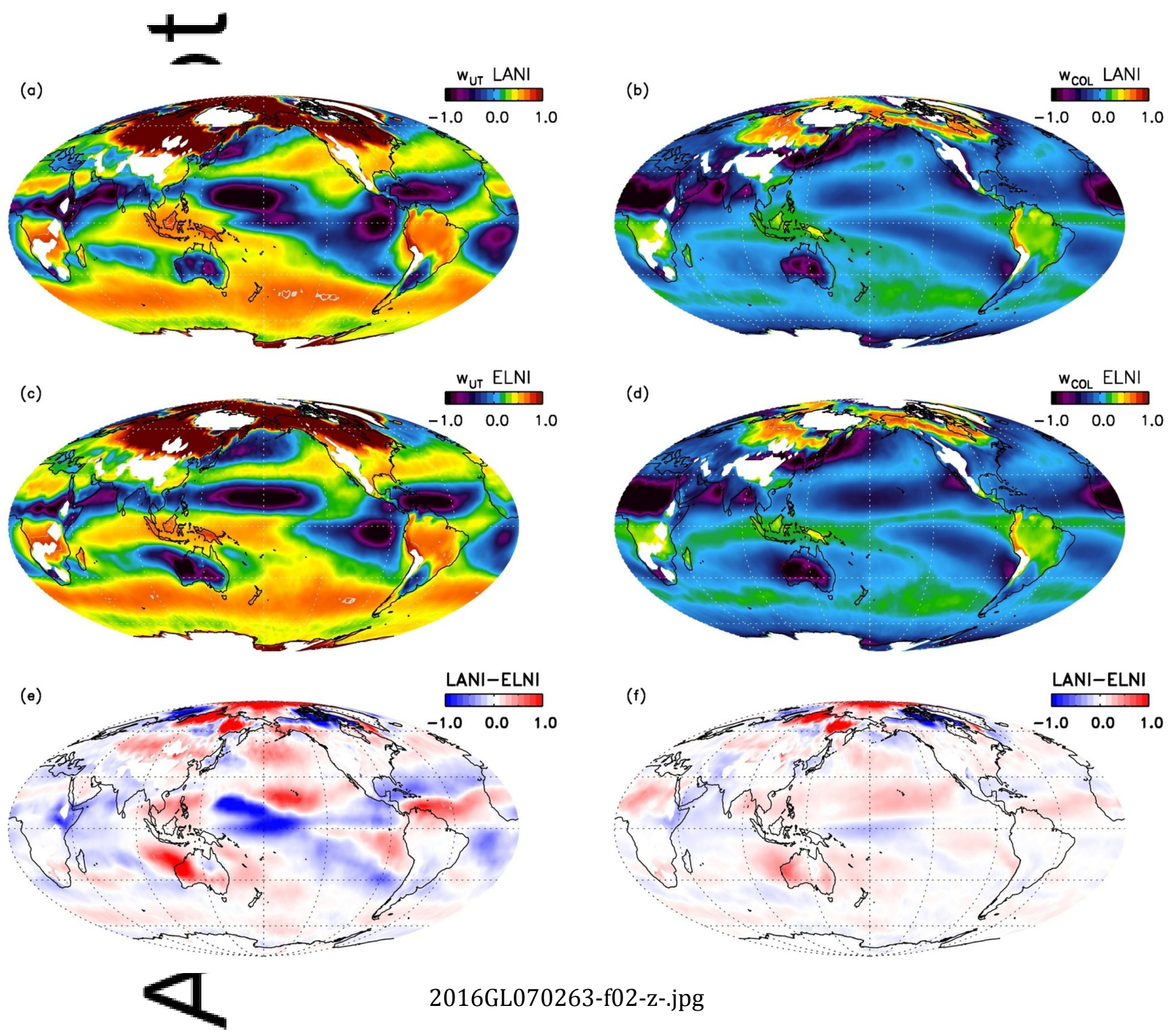

This article is protected by copyright. All rights reserved. 

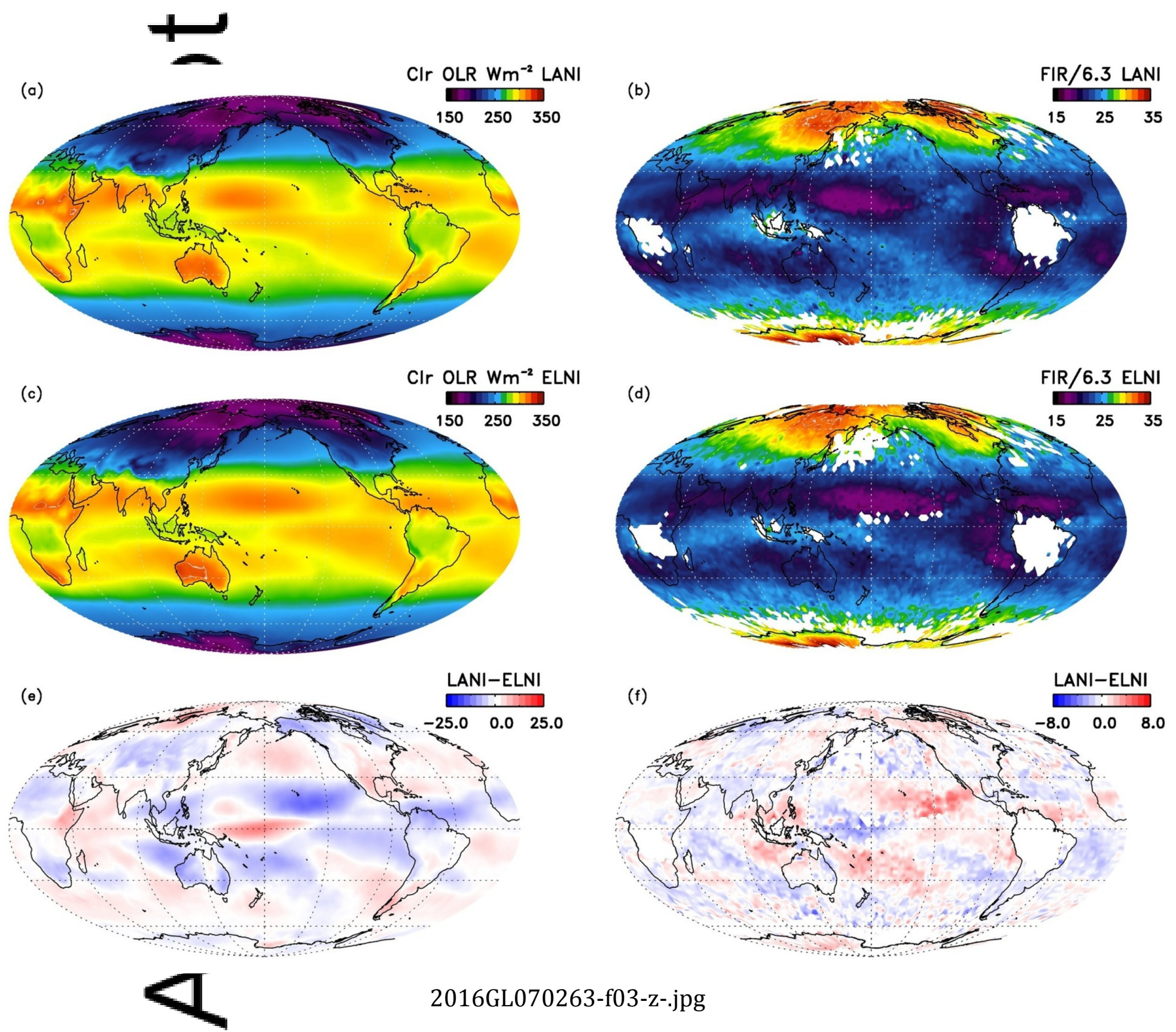

This article is protected by copyright. All rights reserved. 

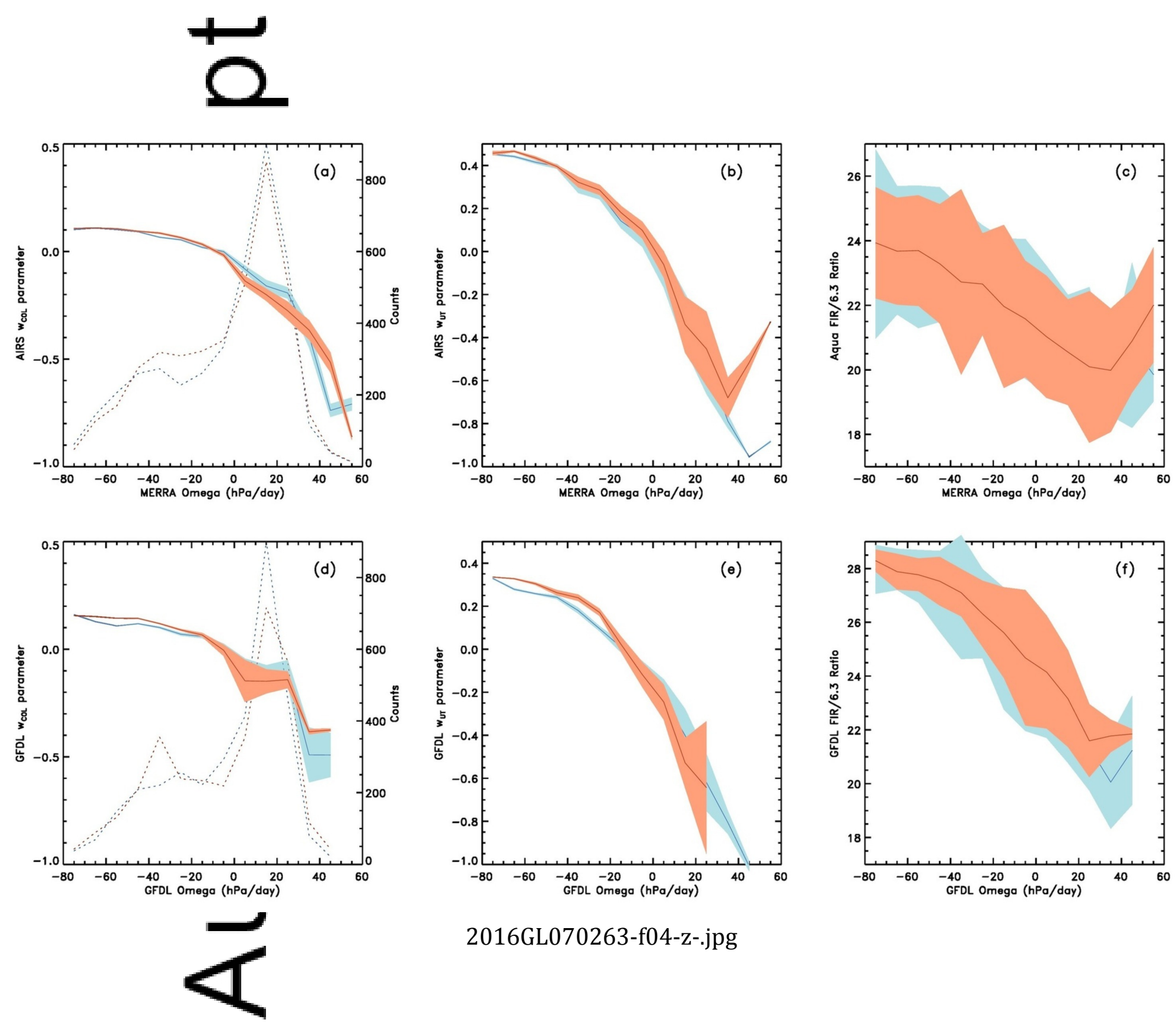

2016GL070263-f04-z-.jpg 